\title{
Efficacy of Fixed-Dose Combination Therapy in the Treatment of Patients with Hypertension Focus on Amlodipine/Valsartan
}

\section{Pedro Marques da Silva}

Núcleo de Investigação Arterial, Medicina IV-Hospital de St ${ }^{\mathrm{a}}$ Marta, CHLC, EPE, Lisbon, Portugal

\section{Contents}

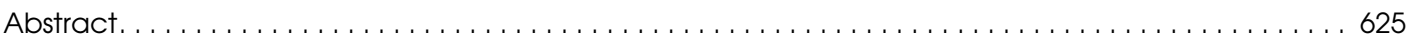

1. Combination Antihypertensive Therapy . . . . . . . . . . . . . . . . . . . . . . . . . 626

2. Rationale for the Use of a Combination of a Renin-Angiotensin-Aldosterone System Inhibitor and a Calcium Channel Blocker . . . . . . . . . . . . . . . . . . . . . . . . . . . . . . . . 627

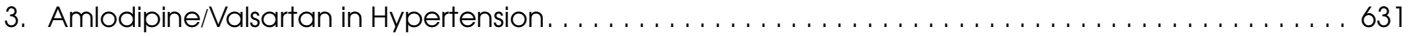

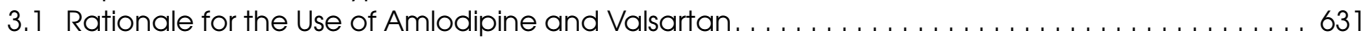

3.2 Amlodipine/Valsartan Fixed-Dose Combination Therapy . . . . . . . . . . . . . . . . 633

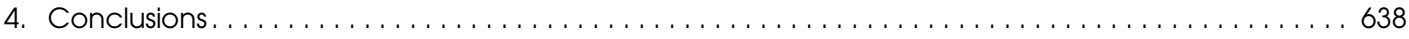

\section{Abstract}

Early initiation of rational and effective combination therapy consisting of antihypertensive drugs with two different and complementary mechanisms of actions is increasingly becoming accepted in clinical practice and by guidelines as a first-line approach to control blood pressure (BP) and prevent cardiovascular outcomes in patients with hypertension. Once-daily combination therapy provides more rapid control of $\mathrm{BP}$, which is important for preventing cardiovascular events, with similar or improved tolerability compared with the component monotherapies, and improved adherence because of regimen simplification. Combination therapy with a calcium channel antagonist (calcium channel blocker [CCB]) and an inhibitor of the renin-angiotensin-aldosterone system (RAAS) is a rational approach to achieve BP goals and provide protection against renal and cardiovascular morbidity and mortality. A number of $\mathrm{CCB} / \mathrm{RAAS}$ inhibitor combinations, including $\mathrm{CCB} /$ angiotensin-converting enzyme (ACE) inhibitor and $\mathrm{CCB}$ / angiotensin II type 1 receptor antagonist (angiotensin receptor blocker [ARB]) combinations are available as fixed-dose formulations. There is substantial evidence for the BP-lowering efficacy of $\mathrm{CCB} / \mathrm{RAAS}$ inhibitor combinations in diverse patient populations, and their use in combination is associated with favourable tolerability and fewer adverse metabolic effects than some other combination therapies. Recent evidence from large outcome trials supports the use of CCB/RAAS inhibitor combinations for reducing the risk of cardiovascular and renal events, particularly in high-risk patients, together with evidence that the benefits of CCB/RAAS 
inhibitor combinations may extend beyond their efficacy in lowering BP in terms of protecting against fatal and nonfatal stroke, myocardial infarction and cardiovascular-related deaths. The efficacy of the CCB amlodipine and the ARB valsartan in lowering BP and protecting against cardiovascular events and stroke across a range of hypertensive patient populations has been established over many years. Fixed-dose amlodipine/valsartan combinations are available in many countries and have shown greater BP reductions and better BP control than the respective monotherapies in diverse patient populations, together with a favourable tolerability profile. Once-daily amlodipine/ valsartan is a rational and convenient treatment option for the effective management of patients with hypertension, improving adherence to antihypertensive medication and protecting against cardiovascular and renal morbidity and mortality.

Current practice guidelines for the management of hypertension, such as the Seventh Report of the US Joint National Committee on Prevention, Detection, Evaluation, and Treatment of High Blood Pressure (JNC 7) ${ }^{[1]}$ and the European Society for Hypertension-European Society of Cardiology (ESH-ESC), ${ }^{[2]}$ define hypertension as systolic blood pressure (SBP) $\geq 140 \mathrm{mmHg}$ and/or diastolic BP (DBP) $\geq 90 \mathrm{mmHg}$. Isolated systolic hypertension is defined as SBP $\geq 140 \mathrm{mmHg}$ and DBP $<90 \mathrm{mmHg}$. The guidelines recommend a BP goal of $<140 / 90 \mathrm{mmHg}$; more stringent goals $(<130 / 80 \mathrm{mmHg})$ are recommended for patients at high cardiovascular risk. ${ }^{[1,2]}$ There is strong evidence demonstrating that antihypertensive agents from several classes, including angiotensin-converting enzyme (ACE) inhibitors, angiotensin II type 1 $\left(\mathrm{AT}_{1}\right)$ receptor antagonists (angiotensin receptor blockers [ARBs]), calcium channel antagonists (calcium channel blockers [CCBs]), $\beta$-blockers and thiazide diuretics, are effective in lowering BP. ${ }^{[3-9]}$

ESH-ESC, WHO, the British Society of Hypertension and the JNC 7 all acknowledge that most hypertensive patients will require two or more antihypertensive agents to reach BP goals associated with reduced risk of cardiovascular events. ${ }^{[1,2,10,11]}$ Furthermore, in the light of recent important hypertension studies published since the 2007 ESH-ESC guidelines, the 2009 reappraisal of the European Guidelines on hypertension management recommends a more individually tailored approach for the management of hyper- tension, particularly in high-risk patients. ${ }^{[12]}$ Early initiation of BP-lowering treatment with a two-drug antihypertensive combination is recommended in patients with stage 2 hypertension (i.e. $\mathrm{BP}>20 / 10 \mathrm{mmHg}$ above $\mathrm{BP}$ goal), ${ }^{[1,2]}$ and in patients with high cardiovascular risk because of the presence of multiple risk factors such as diabetes mellitus or renal or cardiovascular disease, in order to minimize the development or progression of target organ damage or to prevent cardiovascular events. ${ }^{[2,12]}$ The additive BP-lowering effect of two drugs with complementary mechanisms of action facilitates more rapid $\mathrm{BP}$ lowering than with monotherapy while minimizing the individual adverse effects of the component agents, as lower doses of the individual components can be used to achieve a similar or higher level of antihypertensive efficacy. ${ }^{[1,2]}$ Twodrug combination therapies currently available include ACE inhibitor/thiazide diuretic, ARB/ thiazide diuretic, $\mathrm{CCB} /$ thiazide diuretic, $\mathrm{ACE}$ inhibitor/CCB, $\mathrm{ARB} / \mathrm{CCB}$ and $\beta$-blocker/CCB.

\section{Combination Antihypertensive Therapy}

Fixed-dose combinations have a number of advantages over free combinations, including better adherence (because of regimen simplification) and cost savings. ${ }^{[13,14]}$ Meta-analysis of 68 studies of fixed-dose combinations involving a total of 11925 patients found a 26\% decrease in the risk of non-adherence compared with free-drug 
combination strategies, with a $24 \%$ reduction in studies specific to antihypertensive medication. ${ }^{[14]}$ Consequently, as better adherence can translate into improved clinical outcomes, ${ }^{[15]}$ fixed-dose combinations should be considered in patients with hypertension. The possible disadvantage of less flexibility in terms of dosage has been addressed by the current availability of several fixed-dose combinations, marketed in multiple fixed doses, which minimize the inconvenience if the dose of one drug but not the other needs to be increased. ${ }^{[1,12,16]}$ Usually agents from two different classes with complementary mechanisms of action are combined, and the 2009 reappraisal of the European Guidelines, outlining the advantages of combination antihypertensives over monotherapy and discussing preferred drugs, quoted a recent meta-analysis of 42 factorial trials involving a total of 10968 patients that showed that combining two agents from any two classes of antihypertensives is approximately five times more effective than doubling the dose of a single agent, supporting the use of combination therapy as the preferred first-line strategy in the treatment of hypertension. ${ }^{[17]}$ The European Guidelines reappraisal recommends initiation of treatment with a combination of two antihypertensives in patients with a high initial BP or who are at high or very high cardiovascular risk, before target organ damage develops or becomes irreversible, or before cardiovascular events occur. ${ }^{[12]}$

The reappraisal also supports an SBP goal of $<140 \mathrm{mmHg}$ in elderly and very elderly patients, and lowering SBP as much as possible below $140 \mathrm{mmHg}$ in patients with diabetes, while acknowledging the difficulty of reaching a BP goal of $130 / 80 \mathrm{mmHg} .^{[12]}$ In patients with diabetes, the guidelines specify that an inhibitor of the reninangiotensin-aldosterone system (RAAS) should always be included in combination treatment because of its superior protection against initiation or progression of nephropathy..$^{[1,2,12]}$ CCBs are also favoured because of their efficacy in reducing cardiovascular events. ${ }^{[1]}$

Combination treatment should use agents from classes with different and complementary pharmacological profiles. ${ }^{[2]}$ Combining antihypertensive agents with complementary modes of action, e.g. CCBs and RAAS inhibitors, is a rational therapeutic approach that provides more effective control of hypertensive symptoms than equivalent monotherapies. ${ }^{[16,18-22]}$

\section{Rationale for the Use of a Combination of a Renin-Angiotensin-Aldosterone System Inhibitor and a Calcium Channel Blocker}

Dihydropyridine $\mathrm{CCBs}$ such as amlodipine preferentially inhibit calcium influx via the L-type channels of vascular smooth muscle, lowering BP through the resulting reduction in peripheral vascular resistance while promoting cardiac contractility and increasing AV conduction. ${ }^{[18,23,24]}$ The efficacy of dihydropyridine CCBs in lowering BP and preventing cardiovascular outcomes, including stroke and coronary events, is well established, as reviewed in Nathan et al. ${ }^{[23]}$ and Ram. ${ }^{[24]}$ Compelling indications for their use include high-risk coronary disease and diabetes. ${ }^{[1,2]}$ The main adverse events associated with dihydropyridine CCBs include oedema, headache and flushing. ${ }^{[24]}$

The RAAS has a central role in the regulation of cardiovascular, renal and adrenal functions, and is essential to the maintenance of haemodynamic stability. ${ }^{[25,26]}$ Hypertension, diabetic and nondiabetic nephropathy, coronary artery disease and other clinical disease states are well established pathological consequences of overactivity of the RAAS. ${ }^{[25]}$ There is well established evidence for the antihypertensive efficacy of combining RAAS blockade using ACE inhibitors or ARBs with CCBs (reviewed in Chrysant ${ }^{[27]}$ ).

ACE inhibitors inhibit ACE activity, leading to decreased formation of angiotensin II, with a similar downstream effect to that of ARBs. ${ }^{[24]}$ Unlike ARBs, ACE inhibitors prevent the breakdown of bradykinin, which mediates in part their beneficial vascular and endothelial effects, and is also assumed to be the cause of ACE inhibitorinduced cough. ${ }^{[24,28]}$ ACE inhibitor/CCB combinations have been shown to be significantly more effective at lowering BP than monotherapy with either agent alone. ${ }^{[29-34]}$ Compelling indications for the use of ACE inhibitors include heart failure, 
left ventricular dysfunction, post-myocardial infarction, high coronary disease risk, diabetes, chronic kidney disease and recurrent stroke prevention. ${ }^{[1,2]}$

ARBs such as valsartan block the vasoconstricting and aldosterone-secreting activity of angiotensin II via selective inhibition of the binding of angiotensin II to $\mathrm{AT}_{1}$ receptors in the heart, blood vessels and adrenal cortex. ${ }^{[35,36]}$ They have similar BP-lowering efficacy and share similar activity in reversing or inhibiting vasoconstriction, myocardial hypertrophy, vascular hypertrophy and aldosterone secretion to that of ACE inhibitors, and have well established efficacy in preventing or reducing cardiovascular outcomes, including stroke and coronary events. ${ }^{[16,18,23,24]}$ As a class, ARBs are noted for placebo-like tolerability, with transient mild headache, nasopharyngitis and fatigue being the most common ARB-associated adverse events. ${ }^{[2,37]}$ Compelling indications for the use of ARBs include heart failure, diabetes and chronic kidney disease. ${ }^{[1,2]}$ The principal overlapping and complementary indications of ARBs and CCBs in patients with hypertension are summarized in figure 1.

Inhibition of the RAAS with ACE inhibitors or ARBs has gained support as a rational choice for use in combination therapy for the initial treatment of hypertension. ${ }^{[38]}$ RAAS inhibitors are commonly available in combination with diuretics and CCBs, and an RAAS inhibitor in combination with a $\mathrm{CCB}$ (ACE inhibitor/CCB or $\mathrm{ARB} / \mathrm{CCB}$ ) is among the preferred two-drug combinations recommended by guidelines and is supported by a depth of evidence demonstrating effective BP lowering and reduction of cardiovascular events. ${ }^{[12]}$ As previously mentioned, fixed-dose combinations are favoured by the guidelines because of the contribution that simplification of the treatment regimen makes to facilitating compliance. ${ }^{[1,2,12]}$

Combining a dihydropyridine $\mathrm{CCB}$ and an ARB, such as amlodipine and valsartan or amlodipine and olmesartan medoxomil, may not only enhance BP-lowering efficacy compared

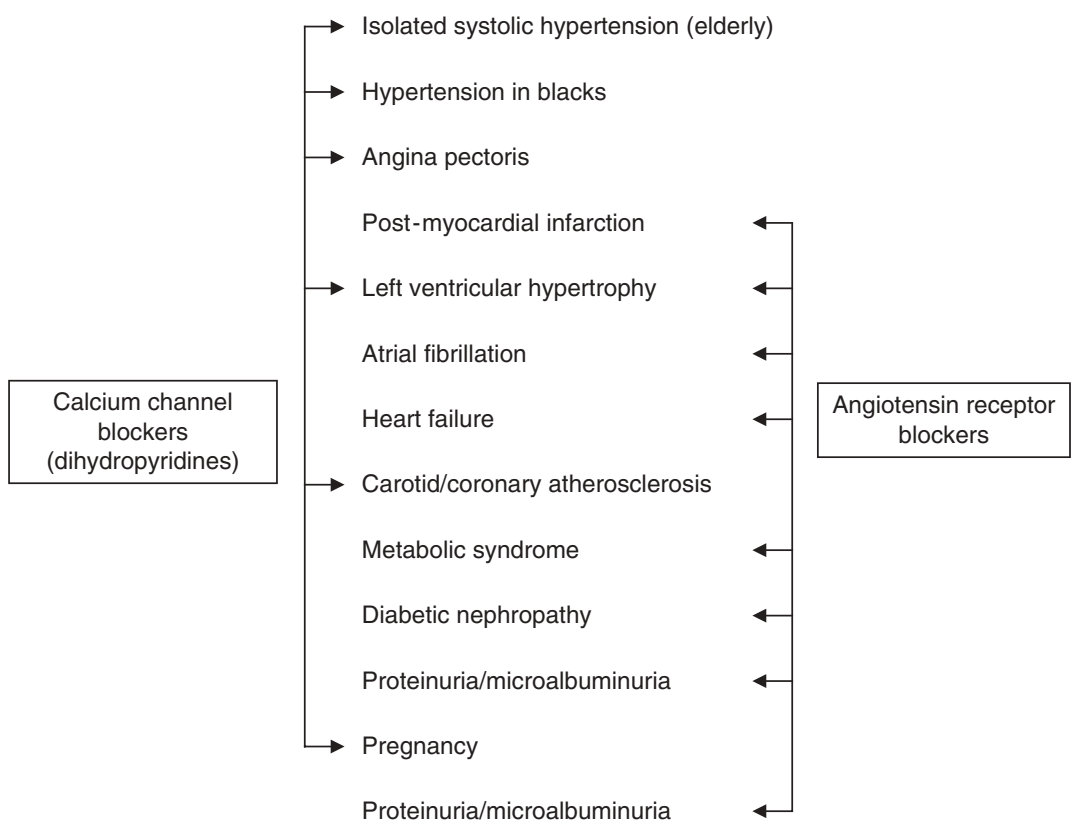

Fig. 1. Principal indications favouring the use of angiotensin II type 1 receptor antagonists (angiotensin receptor blockers) and dihydropyridine calcium channel antagonists (calcium channel blockers) according to the European Society of Hypertension-European Society of Cardiology (ESH-ESC) guidelines for the management of hypertension. ${ }^{[2]}$ Reproduced with permission from Waeber and Ruilope. ${ }^{[16]}$ 
with component monotherapies, but may also offset the counter-regulatory response of the sympathetic nervous system to CCB-induced vasodilation via the sympathetic nervous system moderated by concomitant blockade of the RAAS (as reviewed in Waeber and Ruilope). ${ }^{[22]}$ Consequently, the antihypertensive effect is additive or more than additive. The CCB-mediated renin release and reflex sympathetic nervous system activation is counterbalanced by ARBmediated RAAS antagonism and modulation of sympathetic activity, together with a natriuretic effect that may also contribute to angiotensin II-dependent maintenance of BP. ${ }^{[22]}$ Use of an RAAS-inhibitor in conjunction with a CCB also counteracts pedal oedema, the most common adverse event associated with CCBs. ${ }^{[39]}$ This was clearly demonstrated for valsartan in two recent trials in patients with moderate-to-severe hypertension, in which peripheral oedema was reported in $5.4 \%$ of amlodipine/valsartan recipients compared with $8.7 \%$ of those receiving amlodipine monotherapy $(\mathrm{p}<0.05) .{ }^{[21]}$ Thus, combination therapy helps alleviate adverse events. Furthermore, neither CCBs nor ARBs are associated with increased risk of new-onset diabetes in hypertensive patients, unlike diuretics and $\beta$-blockers. ${ }^{[7,40-42]}$ While CCBs are metabolically neutral, ARBs in fact delay or reduce the risk of diabetes. ${ }^{[43,44]}$ That RAAS inhibitors play an important role in preventing type 2 diabetes was confirmed by a meta-analysis of 12 randomized controlled clinical trials of ARBs or ACE inhibitors that showed an overall highly significant $25 \%$ reduction in the incidence of new-onset diabetes $(23 \%$ for ARBs and $27 \%$ for ACE inhibitors) compared with other antihypertensive agents or placebo. ${ }^{[4]}$ This finding, based on data from a total of 72333 non-diabetic patients, supports the choice of an ARB or ACE inhibitor as a logical component of first-line antihypertensive therapy, particularly in patients at increased risk of diabetes. Although the mechanisms are not fully established, the protective effect of ARBs and ACE inhibitors may involve improved insulin sensitivity as a result of the effect on skeletal muscle blood flow of peripheral vasodilation and/or the promotion of the differentiation of pre-adipocytes to mature adipocytes as a result of increased adiponectin levels. ${ }^{[43]}$ A direct protective effect on pancreatic $\beta$-cell function is also possible. ${ }^{[43]}$

There is robust evidence supporting the efficacy in lowering BP and in preventing or reducing cardiovascular morbidity of RAAS blockade using ACE inhibitors or ARBs, and of CCBs in reducing $\mathrm{BP}$ and the complications of hypertension in diverse patient populations, including patients with diabetes, the elderly and patients at high risk of cardiovascular events (reviewed in $\mathrm{Ram}^{[24]}$ ). For these reasons, RAAS inhibitorbased combination therapies have been gaining increasing support as initial treatment of hypertension. ${ }^{[38,45]}$ The efficacy of an RAAS inhibitor-based strategy alone or in combination with a diuretic in lowering BP and preventing hypertension-associated complications such as cardiovascular events and stroke was shown in part by intervention studies such as $\operatorname{LIFE}^{[7]}$ (see table I for trial names) and SCOPE, ${ }^{[46]}$ which used strategies based on an ARB (losartan and candesartan cilexetil, respectively) with the addition of hydrochlorothiazide, and in PROGRESS, where the combination of an ACE inhibitor and diuretic (perindopril plus indapamide) reduced the risk of stroke in hypertensive patients. ${ }^{[8,47]}$

Table I. Trial names

\begin{tabular}{|c|c|}
\hline$\overline{\mathrm{ACCOMPLISH}}$ & $\begin{array}{l}\text { Avoiding Cardiovascular Events through } \\
\text { Combination Therapy in Patients Living with } \\
\text { Systolic Hypertension }\end{array}$ \\
\hline ASCOT & Anglo-Scandinavian Cardiac Outcomes Trial \\
\hline ASCOT-BPLA & $\begin{array}{l}\text { Anglo-Scandinavian Cardiac Outcomes Trial- } \\
\text { Blood Pressure Lowering Arm }\end{array}$ \\
\hline LIFE & $\begin{array}{l}\text { Losartan Intervention For Endpoint reduction in } \\
\text { hypertension study }\end{array}$ \\
\hline ONTARGET & $\begin{array}{l}\text { Ongoing Telmisartan Alone and in Combination } \\
\text { with Ramipril Global Endpoint Trial }\end{array}$ \\
\hline PROGRESS & $\begin{array}{l}\text { Perindopril Protection Against Recurrent Stroke } \\
\text { Study }\end{array}$ \\
\hline SCOPE & Study on Cognition and Prognosis in the Elderly \\
\hline Val-HeFT & Valsartan Heart Failure Trial \\
\hline VALIANT & Valsartan in Acute Myocardial Infarction Trial \\
\hline VALUE & $\begin{array}{l}\text { Valsartan Antihypertensive Long-term Use } \\
\text { Evaluation }\end{array}$ \\
\hline
\end{tabular}


Other landmark trials have demonstrated the efficacy of combination therapy for BP lowering and subsequent improvements in cardiovascular morbidity and mortality. For example, the recent ACCOMPLISH ${ }^{[48]}$ study results strongly suggest that CCB-based treatment in combination with an $\mathrm{ACE}$ inhibitor is preferable to a diuretic/ACE inhibitor combination in high-risk hypertensive patients. In total, 11506 patients aged $\geq 55$ years with SBP $>160 \mathrm{mmHg}$ or currently receiving antihypertensive medication and who had evidence of cardiovascular or renal disease or targetorgan damage were enrolled in this study; $60 \%$ had diabetes and many had coronary disease. ACCOMPLISH was stopped early after a mean follow-up of 36 months because the benazepril/amlodipine strategy was more effective than treatment with benazepril/hydrochlorothiazide. Overall, $73 \%$ of patients achieved a target BP of $<140 / 90 \mathrm{mmHg}$ within 6 months of starting combination therapy. ${ }^{[49]}$ However, despite similar BP lowering with the two strategies, the RAAS inhibitor/CCB combination reduced the relative risk of cardiovascular morbidity and mortality by $19.6 \%$ compared with the RAAS inhibitor/diuretic combination, ${ }^{[48]}$ challenging current treatment guidelines for hypertension, some of which indicated a preference for the inclusion of a thiazide diuretic in combination regimens. ${ }^{[1]}$ The findings of studies such as ACCOMPLISH support the early use of combination therapy as the initial antihypertensive strategy in patients with hypertension, particularly those at high risk of cardiovascular events, and suggest that an RAAS inhibitor/CCB combination may provide superior cardiovascular outcomes. However, the choice of initial drugs should also consider compelling indications or contraindications, co-morbid conditions, the tolerability profile of the component agents and the clinician's experience.

Regarding choice of antihypertensive agents, the suggestion that ARBs may be inferior to ACE inhibitors in protecting against myocardial infarction has been largely undermined by the results of ONTARGET, ${ }^{[50]}$ together with those of meta-analyses of ACE inhibitors and ARBs that included more recent as well as older trials, which concluded that ACE inhibitors and ARBs offer the same protection against myocardial infarction. ${ }^{[51,52]}$ ONTARGET randomized a total of 25620 patients with vascular disease or high-risk diabetes to treatment based on the ARB telmisartan (8542 patients), the ACE inhibitor ramipril (8576) or a combination of the two drugs (8502). ARB monotherapy and combination therapy were more effective at lowering BP than the ACE inhibitor strategy ( $p<0.001$ for combination therapy vs ramipril), and telmisartan was not inferior to ramipril for preventing the primary outcome of death from cardiovascular causes, myocardial infarction, stroke or hospitalization for heart failure. Similarly, the ARB and ACE inhibitor strategies provided similar levels of protection against death from cardiovascular causes, myocardial infarction or stroke, and against the component outcomes: myocardial infarction, stroke, death from cardiovascular causes and all-cause death. ${ }^{[50]}$ However, the combined ARB/ACE inhibitor strategy did not reduce cardiovascular or renal endpoints compared with monotherapy and was associated with more renal adverse events, and use of such a combination is not generally supported. ${ }^{[12]}$

An amlodipine-based regimen with the addition of an ACE inhibitor (perindopril) was compared with a $\beta$-blocker (atenolol)-based regimen with the addition of a diuretic (bendroflumethiazide) in the ASCOT-BPLA study of 19257 hypertensive patients at risk of developing cardiovascular events ( $\geq 3$ cardiovascular risk factors at baseline). ${ }^{[53]}$ Amlodipine-based therapy was more effective than atenolol-based therapy in lowering BP throughout the study, more effectively reduced total cardiovascular events, and induced fewer cases of new-onset diabetes than atenolol-based therapy. After a median of 5.5 years of follow-up, the difference between strategies in all-cause mortality was $11 \%$ in favour of the amlodipine-based regimen (hazard ratio [HR] 0.89, 95\% CI 0.81, 0.99; $\mathrm{p}=0.0247$ ), contributed to by a $24 \%$ reduction in cardiovascular mortality (HR 0.76, 95\% CI 0.65, 0.90; $\mathrm{p}=0.001)$. Other secondary endpoints also favoured the amlodipine-based regimen, with a $23 \%$ reduction in fatal and nonfatal stroke 
$(p=0.0003)$, a $13 \%$ reduction in total coronary events $(p=0.007)$, a $16 \%$ reduction in total cardiovascular events and procedures $(\mathrm{p}<0.001)$, a $13 \%$ reduction in nonfatal myocardial infarction (excluding silent events) and fatal coronary heart disease $(\mathrm{p}=0.0458)$, and a $30 \%$ reduction in new-onset diabetes $(\mathrm{p}<0.0001)$. The primary endpoint (all nonfatal myocardial infarction plus fatal coronary heart disease) was reduced by $10 \%$ with the amlodipine-based regimen, although the difference had not reached statistical significance when the study was terminated early because of the superiority of the amlodipine/ACE inhibitor regimen. ${ }^{[53]}$

In ASCOT, the use of amlodipine with or without perindopril was associated with a $34 \%$ reduction in the risk for new-onset diabetes compared with use of atenolol with or without thiazide, regardless of the baseline risk category. ${ }^{[54]}$ While fasting plasma glucose was the most robust risk factor for new-onset diabetes, amlodipinebased therapy was the strongest protective factor, suggesting amlodipine as a rational consideration when choosing antihypertensive agents in routine clinical practice. ${ }^{[54]}$

As noted above, the benefits of first-line therapy with RAAS inhibitors and $\mathrm{CCBs}$ in reducing cardiovascular risk have been firmly established. RAAS inhibitor/CCB combination therapy has also been shown to effectively prevent cardiovascular events in several large-scale cardiovascular outcomes trials using ACE inhibitor/CCB regimens. ${ }^{[48,55]}$ Furthermore, a recent trial showed that amlodipine/valsartan (with potential addition of diuretics or $\beta$-blockers) improved measures of diastolic dysfunction in patients with hypertension and diastolic dysfunction. ${ }^{[56]}$ The trial randomized patients with stage II hypertension and echocardiographic evidence of diastolic dysfunction, and was designed to examine whether intensive BP lowering with an amlodipine/valsartan-based regimen improved parameters of hypertensive endorgan damage. Diabetes and heart failure were exclusion criteria. Therapy was initiated with amlodipine/valsartan $5 \mathrm{mg} / 160 \mathrm{mg}$ and uptitrated with additional antihypertensive medications being added if required to reach intensive versus standard BP control (SBP $<130 \mathrm{mmHg}$ vs SBP
$<140 \mathrm{mmHg}$ ). BP was reduced significantly in both the intensive and the standard control arms, and there were significant improvements in measures of diastolic function and vascular function in both arms. Mean \pm SD mitral annular relaxation velocity (the primary efficacy endpoint) increased from $7.6 \pm 1.1$ to $9.2 \pm 1.7 \mathrm{~cm} / \mathrm{s}$ in the intensive control arm and from $7.5 \pm 1.3$ to $9.0 \pm 1.9$ $\mathrm{cm} / \mathrm{s}$ in the standard control arm $(\mathrm{p}<0.0001$ for both groups), a change of $1.54 \pm 1.4 \mathrm{~cm} / \mathrm{sec}$ and $1.48 \pm 1.6 \mathrm{~cm} / \mathrm{sec}$ in the intensive versus standard control arms, respectively, from baseline to week $24(p=0.58$ between groups). Although no differences in the achieved improvement in myocardial relaxation velocity or measures of arterial stiffness were observed between strategies, the degree of improvement was associated with the extent of SBP reduction. ${ }^{[56]}$ The study further supports the role of fixed-dose CCB/RAAS inhibitor combinations for cardiovascular risk reduction in hypertensive patients.

\section{Amlodipine/Valsartan in Hypertension}

\section{1 Rationale for the Use of Amlodipine and Valsartan}

The efficacy of amlodipine and valsartan as monotherapies in the treatment of hypertension has been well established over many years of clinical studies and clinical practice. A recent article by Black et al. ${ }^{[37]}$ reviewed the experience of more than a decade of valsartan use in the management of hypertension. In brief, valsartan has been studied in more than 100000 patients and has been shown in a number of large-scale hypertension studies to demonstrate dose-dependent efficacy in lowering SBP and DBP over a oncedaily dosage range of $80-320 \mathrm{mg}$ across a range of adult hypertensive patient populations. ${ }^{[37]}$ These include the elderly, obese patients, patients at high risk of cardiovascular events, patients with diabetes and patients with chronic kidney disease, regardless of race, age, sex or hypertension severity. The BP-lowering efficacy of valsartan is similar to that of other antihypertensive agents, including ACE inhibitors, $\beta$-blockers, diuretics, CCBs and other ARBs. Large outcome trials 
have demonstrated the efficacy of valsartan in protecting against cardiovascular events and stroke in various patient populations, with a similar efficacy and a more favourable tolerability profile to that of ACE inhibitors. Valsartan has also been shown to improve markers of chronic kidney disease, such as albuminuria and protein excretion, in diabetic and non-diabetic patients. The drug has also been shown to be efficacious in patients with isolated systolic hypertension. The ability of valsartan to provide adequate and consistent BP control over the full dosing interval has been demonstrated in a number of studies using ambulatory BP monitoring, with similar or greater 24-hour BP reductions to those produced by clinically comparable doses of losartan, olmesartan medoxomil, telmisartan, aliskiren and amlodipine. ${ }^{[37]}$ As previously noted, valsartan shares a placebo-like tolerability profile with other ARBs, independent of dose up to a tested level of $320 \mathrm{mg} /$ day (the optimal starting dose of valsartan has been established as $160 \mathrm{mg}$ /day in essential hypertension) and consistent across different patient populations. ${ }^{[37]}$ However, limited data are available on the paediatric use of valsartan. Valsartan monotherapy is associated with significantly lower rates of peripheral oedema than amlodipine monotherapy. ${ }^{[21]}$

Short- and long-term studies reviewed by Haria and Wagstaff ${ }^{[57]}$ indicate that once-daily amlodipine monotherapy in doses of $2.5-10 \mathrm{mg} /$ day is an effective antihypertensive treatment, lowering mild-to-moderate $\mathrm{BP}$ with similar efficacy to other established agents, such as ACE inhibitors, $\beta$-blockers, diuretics, $\mathrm{ARBs}$ and other $\mathrm{CCBs} .{ }^{[57]}$ Amlodipine significantly reduces SBP and DBP in a dose-dependent manner in patients with essential hypertension, including young and elderly populations, and patients with renal dysfunction, diabetes or hyperlipidaemia, regardless of race. ${ }^{[18,57]}$ Amlodipine also reduces mean ambulatory BP throughout a 24-hour dose interval, without accompanying reflex tachycardia or postural hypotension, and with a tolerability profile generally comparable to that of other conventional antihypertensive agents. ${ }^{[57]}$ The main adverse events associated with amlodipine monotherapy are dose-dependent vasodilatory effects including oedema, headache, flushing and dizziness. However, the main amlodipine-related adverse event, peripheral oedema, is usually mild or moderate in severity and generally tolerated without treatment withdrawal. ${ }^{[57]}$

The benefits of valsartan in reducing cardiovascular endpoints have been shown in largescale trials such as Val-HeFT (in patients with heart failure), ${ }^{[58-62]}$ VALIANT (in patients with previous myocardial infarction $)^{[63]}$ and VALUE. ${ }^{[64,65]}$ Specifically, in the VALUE trial of 15245 patients aged $\geq 50$ years with hypertension and at high risk of cardiac events (one or more prespecified risk factors or diseases), both valsartan and amlodipine reduced cardiac morbidity and mortality with no significant differences between the two drugs in terms of the composite endpoint of cardiac mortality and morbidity (HR 1.04, 95\% CI $0.94,1.15 ; \mathrm{p}=0.49$ ) after a mean followup of 4.2 years. However, although achievement of the BP target of $<140 / 90 \mathrm{mmHg}$ was similar in the two groups at the end of the study $(56 \%$ in the valsartan group and $62 \%$ in the amlodipine group), there were differences in BP lowering favouring the amlodipine-based regimen, particularly in the first year. As the majority of strokes observed occurred in the first 6 months of the study, rising to $76 \%$ by the end of the first year, these findings emphasize the importance of rapid control of BP to achieve improvements in cardiovascular outcome in patients at high cardiovascular risk. ${ }^{[64]}$ In VALUE, treatment commenced with valsartan $80 \mathrm{mg}$ /day or amlodipine $5 \mathrm{mg}$ /day; doses could be uptitrated and further antihypertensive drugs could be added if necessary to achieve BP control. However, it should be noted that valsartan could be titrated to only $160 \mathrm{mg}$, while amlodipine could be titrated to $10 \mathrm{mg}$, indicating possible underdosing of valsartan in the light of its use at doses up to $320 \mathrm{mg}$ in subsequent trials.

The differences in between-group BP levels limited the ability of VALUE to compare the effects of valsartan and amlodipine on cardiac endpoints. However, post hoc analysis of tightlypaired cohorts of patients who achieved similar BP control at 6 months showed that combined cardiac events, myocardial infarction, stroke and 
mortality were almost identical for both regimens. ${ }^{[66]}$ The only exception was hospitalization for heart failure, which was significantly lower in the valsartan group. This, along with a significantly lower rate of new-onset diabetes in patients receiving valsartan, ${ }^{[67]}$ suggests that valsartan may offer benefits beyond BP lowering. For example, during a median follow-up of 3.1 years in the Jikei Heart Study, similar reductions in BP and similar rates of BP control were achieved by the addition of valsartan to standard cardiovascular treatment (including $\mathrm{CCBs}$ in $67 \%$ of patients) or by increasing the dose or number of standard drugs in Japanese patients with cardiovascular disease. ${ }^{[68]}$ However, the primary endpoint of a composite of cardiovascular morbidity and mortality was reached by significantly fewer patients treated with the valsartan-based strategy than in those given additional non-ARB treatment $(6.0 \%$ vs $9.7 \%$, $\mathrm{p}=0.0002$; HR 0.61$)$. This $39 \%$ relative risk reduction was driven by reductions in stroke $(40 \%$ reduction), angina pectoris (65\% reduction), dissecting aortic aneurysm ( $81 \%$ reduction) and heart failure (47\% reduction). These benefits were observed across various subgroups.

In the recent KYOTO HEART study, the addition of valsartan to standard treatment in high-risk Japanese patients with uncontrolled hypertension was significantly more effective in preventing the primary endpoint (a composite of fatal and nonfatal cardiovascular events) and individual cardiovascular endpoints (angina, stroke) than non-ARB conventional antihypertensive treatment. ${ }^{[69]}$ Of interest, $63 \%$ of patients in the valsartan group were using CCBs at 12 months to assist in reaching BP targets of $<140 / 90 \mathrm{mmHg}(<130 / 80 \mathrm{mmHg}$ in patients with diabetes or renal disease). For a similar degree of BP lowering in each group, the valsartan-based strategy was associated with a $45 \%$ risk reduction in the primary endpoint $(5.5 \%$ vs $10.2 \%$; $\mathrm{p}=0.00001)$, a $45 \%$ risk reduction in stroke $(1.6 \%$ vs $3.0 \% ; \mathrm{p}=0.1488)$ and a $49 \%$ risk reduction in angina $(1.5 \%$ vs $2.9 \% ; \mathrm{p}=0.01058)$ compared with the non-ARB strategy. There was a nonsignificant $35 \%$ reduction in the risk of acute myocardial infarction with the valsartan-based strategy. The study was terminated early after a median follow-up of 3.27 years because of the unequivocal benefit in the valsartan group. ${ }^{[69]}$ These findings suggest that a valsartan-based strategy in which the majority of patients also received a CCB provided a cardiovascular protective effect in a high-risk Japanese hypertensive population. Asians may be particularly receptive to the protective effects of ARBs, and whether the benefits will fully translate to Western populations is unclear.

\subsection{Amlodipine/Valsartan Fixed-Dose Combination Therapy}

Fixed-dose oral combinations of amlodipine/ valsartan and amlodipine/olmesartan medoxomil are available in several European countries for the treatment of hypertension in patients inadequately controlled with amlodipine and valsartan monotherapy, and in the US for patients whose BP is inadequately controlled with amlodipine (or another $\mathrm{CCB}$ ) and valsartan (or another ARB) monotherapy. Furthermore, two other $\mathrm{CCB} / \mathrm{ARB}$ single-pill formulations are available in other regions (amlodipine/losartan) ${ }^{[70]}$ or undergoing development (amlodipine/telmisartan). ${ }^{[71]}$ The introduction of an amlodipine/valsartan/ hydrochlorothiazide combination can also be noted, supporting the recommendations of the 2009 reappraisal of the European Guidelines that an RAAS inhibitor, a CCB and a diuretic at effective doses is the most rational combination when two drugs are insufficient to achieve BP control. ${ }^{[12]}$

Two similarly designed pivotal studies involving a total of 3161 adult patients with mild-tomoderate hypertension demonstrated the efficacy and safety of fixed-dose amlodipine/valsartan compared with their component monotherapies and placebo. ${ }^{[21]}$ The studies evaluated a range of combinations of amlodipine/valsartan, including the widely used dose of $5 \mathrm{mg} / 160 \mathrm{mg}$ once daily. Each dosage of combination therapy produced significantly greater BP reductions than either component or placebo. Table II and figure 2 (study 1) and table III and figure 3 (study 2) summarize the mean BP reductions at study end (after 8 weeks of double-blind treatment) for the 
Table II. Mean reductions in sitting systolic/diastolic blood pressure (SBP/DBP, $\mathrm{mmHg}$ ) after 8 weeks of treatment with different doses of amlodipine and valsartan given alone or in combination in 1911 patients with mild-to-moderate essential hypertension (mean DBP 95-109 $\mathrm{mmHg}$ ) [data from study 1, Philipp et al. $\left.{ }^{[21]}\right]$

\begin{tabular}{|c|c|c|c|c|c|}
\hline \multirow[t]{2}{*}{ Amlodipine dose $(\mathrm{mg})$} & \multicolumn{5}{|c|}{ Valsartan dose $(\mathrm{mg})$} \\
\hline & 0 & 40 & 80 & 160 & 320 \\
\hline$\overline{0^{a}}$ & $7.3 / 7.1$ & $11.8 / 10.1$ & $12.9 / 9.7$ & $15.1 / 11.0$ & $15.7 / 13.4$ \\
\hline 2.5 & $12.4 / 9.3$ & $15.5^{*+} / 10.8$ & $17.0^{*+} / 13.4^{* \dagger}$ & $16.7^{\dagger} / 13.3^{*+}$ & $18.3^{\dagger} / 14.2^{* \dagger}$ \\
\hline 5 & $15.1 / 11.5$ & $19.6^{* t} / 14.6^{* t}$ & $20.8^{*+} / 14.5^{* \dagger}$ & $19.5^{*+} / 14.2^{*+}$ & $22.7^{* t} / 15.9^{*+}$ \\
\hline
\end{tabular}

a Patients received placebo.

* $p<0.05$ vs the same dose of valsartan monotherapy; $+p<0.05$ vs the same dose of amlodipine monotherapy.

combinations and component monotherapies. For each dosage of active treatment, the mean reduction in BP was significantly greater than that with placebo. The BP-lowering efficacy of combination therapy increased with increasing dose over the range of fixed doses studied. Except for amlodipine/valsartan $2.5 \mathrm{mg} / 40 \mathrm{mg}$ in study 1 , co-administration of amlodipine with valsartan was significantly more effective than equivalent doses of monotherapy. In study 1, amlodipine/ valsartan $5 \mathrm{mg} / 160 \mathrm{mg}$, probably the most widely used dose in clinical practice internationally, was very effective at lowering $\mathrm{BP}$, reducing mean seated SBP by $19.5 \mathrm{mmHg}$ from baseline and mean seated DBP by $14.2 \mathrm{mmHg}$. Amlodipine/ valsartan $5 \mathrm{mg} / 40 \mathrm{mg}$ and $5 \mathrm{mg} / 80 \mathrm{mg}$ were similarly effective in reducing BP, with a small additional reduction in $\mathrm{BP}$ when the combination was given

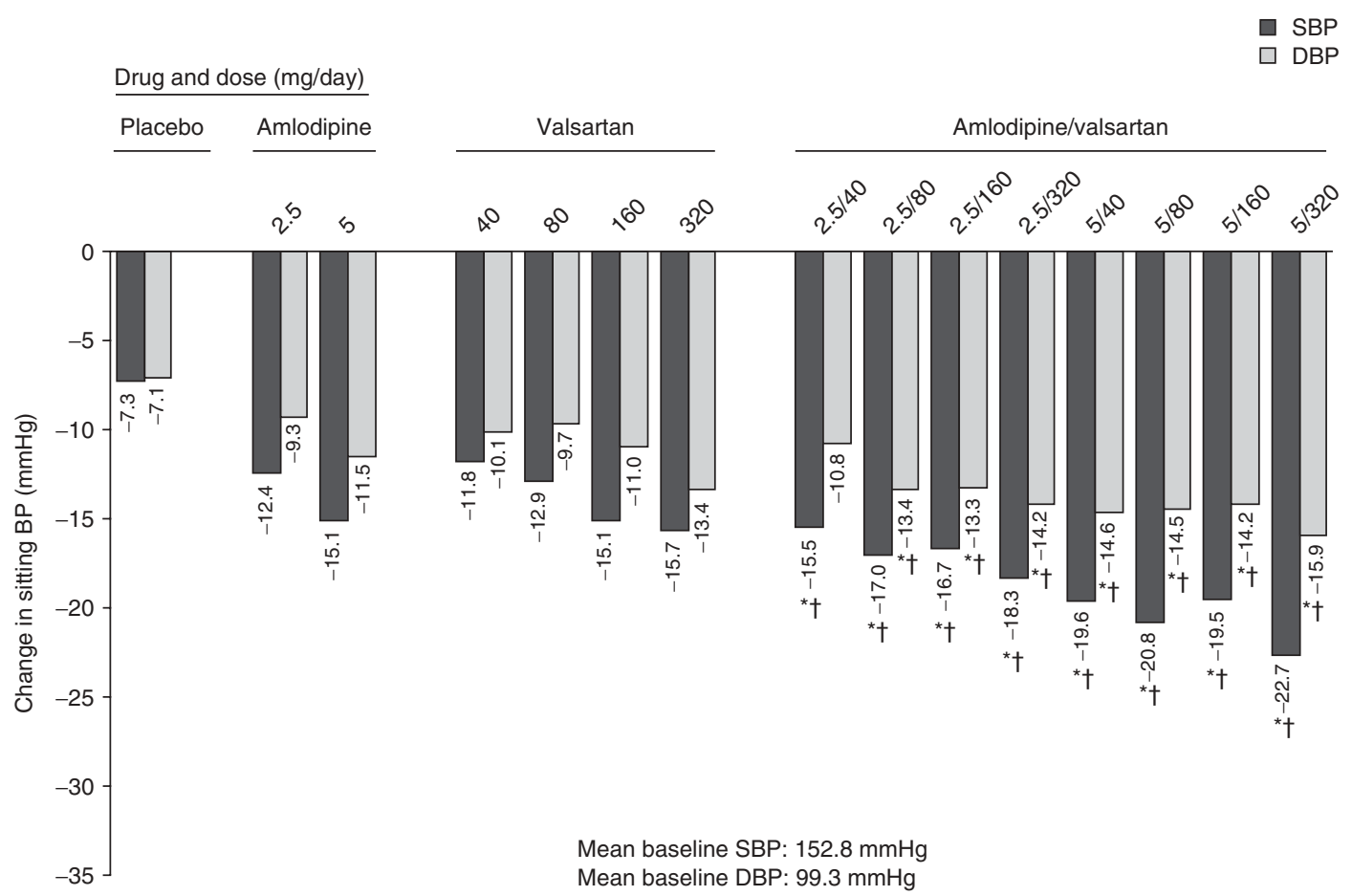

Fig. 2. Mean change from baseline in sitting blood pressure (BP) after 8 weeks of treatment with different doses of amlodipine or valsartan, alone or in combination (study 1 of the Philipp et al. ${ }^{[21]}$ trial). $\mathbf{D B P}=$ diastolic blood pressure; $\mathbf{S B P}=$ systolic blood pressure. ${ }^{*} p<0.05$ vs the same dose of valsartan monotherapy; $+p<0.05$ vs the same dose of amlodipine monotherapy. All active treatments $p<0.05$ vs placebo. 
Table III. Mean reductions in sitting systolic/diastolic blood pressure (SBP/DBP, $\mathrm{mmHg}$ ) after 8 weeks of treatment with different doses of amlodipine and valsartan given alone or in combination in 1250 patients with mild-to-moderate essential hypertension (mean DBP 95-109 mmHg) [data from study 2, Philipp et al. ${ }^{[21]}$

\begin{tabular}{llll}
\hline Amlodipine dose $(\mathrm{mg})$ & \multicolumn{3}{l}{ Valsartan dose $(\mathrm{mg})$} \\
\cline { 2 - 4 } & $0^{\mathrm{a}}$ & 160 & 320 \\
\hline $0^{\mathrm{a}}$ & $12.9 / 8.8$ & $20.2 / 13.3$ & $19.8 / 13.3$ \\
10 & $24.1 / 15.6$ & $27.8^{*+} / 17.6^{*+}$ & $28.4^{*+} / 18.6^{*+}$ \\
\hline
\end{tabular}

a Patients received placebo.

$* p<0.05$ vs the same dose of valsartan monotherapy; $+p<0.05$ vs same dose of amlodipine monotherapy.

at the highest dose evaluated, $5 \mathrm{mg} / 320 \mathrm{mg}$. In study 2 , the two combinations evaluated, amlodipine/valsartan $10 \mathrm{mg} / 160 \mathrm{mg}$ and $10 \mathrm{mg} / 320 \mathrm{mg}$, were both very effective in lowering $\mathrm{BP} .{ }^{[21]} \mathrm{BP}$ control (defined as mean seated DBP $<90 \mathrm{mmHg}$ ) was highest with combination therapy and a positive dose response was observed, reaching $82.5 \%$ in study 1 and $84.1 \%$ in study 2 . The lowest rates of BP control were with placebo $(33.9 \%$ and $42.6 \%$ in study 1 and study 2 , respectively). ${ }^{[21]}$ Sub- group analysis showed that amlodipine/valsartan was also associated with greater BP-lowering effects than the component monotherapies or placebo across all subgroups evaluated, specifically in patients with stage 2 hypertension, the elderly (age $\geq 65$ years), younger patients (age $<65$ years), Black patients and White patients. ${ }^{[72]}$

Analysis of the combined safety population of 3155 patients showed that combination treatment was generally well tolerated, regardless of age, race or sex. ${ }^{[21]}$ There was no significant difference in overall adverse event rates between recipients of amlodipine/valsartan, amlodipine monotherapy or placebo. However, there was a significant difference in overall adverse events between amlodipine/valsartan and valsartan monotherapy $(p<0.05)$. Figure 4 summarizes the tolerability data for the combined safety population. ${ }^{[21]}$ The incidence of peripheral oedema was significantly lower with combination therapy compared with amlodipine monotherapy $(5.4 \%$ vs $8.7 \%, \mathrm{p}=0.014)$, significantly higher than with valsartan monotherapy $(2.1 \%)$, and statistically

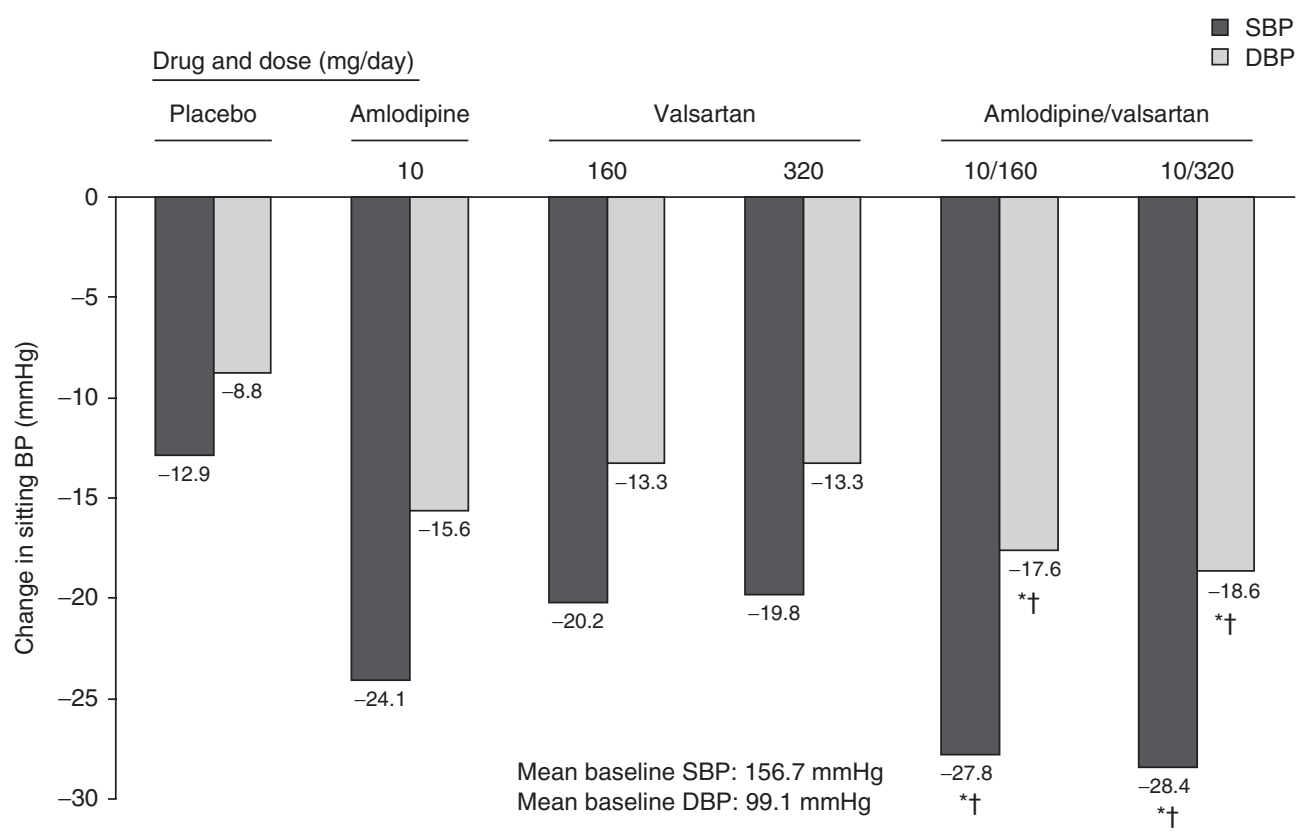

Fig. 3. Mean change from baseline in sitting blood pressure (BP) after 8 weeks of treatment with different doses of amlodipine or valsartan, alone or in combination (study 2 of the Philipp et al. ${ }^{[21]}$ trial). DBP=diastolic blood pressure; $\mathbf{S B P}=$ systolic blood pressure. ${ }^{*} p<0.05$ vs the same dose of valsartan monotherapy; $+p<0.05$ vs the same dose of amlodipine monotherapy. All active treatments $p<0.05$ vs placebo. 


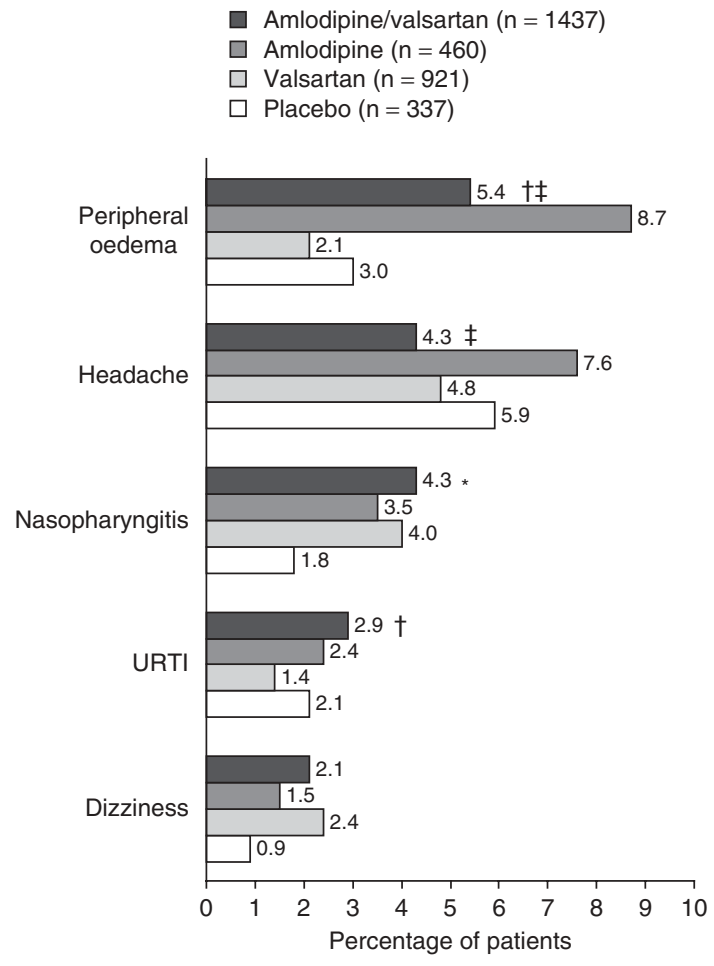

Fig. 4. Pooled tolerability data (\%) from 3155 patients with mild-tomoderate hypertension treated in two randomized, double-blind, 8-week factorial trials of different doses of amlodipine and valsartan, alone or in combination. ${ }^{[21]}$ Adverse events are those reported in $\geq 2 \%$ of patients treated with amlodipine/valsartan. Reproduced with permission from Plosker and Robinson. ${ }^{[73]}$ URTI= upper respiratory tract infection. ${ }^{*} p<0.05$ vs placebo; $+p<0.05$ vs valsartan; $\ddagger \mathrm{p}<0.05$ vs amlodipine.

similar to that with placebo $(3.0 \%)$. The lower incidence of peripheral oedema associated with combination therapy was likely to be related to a decrease in both arteriolar and venous resistance, in contrast to a reduction only in arteriolar resistance that would be anticipated with amlodipine. Headache was significantly lower in amlodipine/valsartan recipients compared with those receiving amlodipine monotherapy $(4.3 \%$ vs $7.6 \%, \mathrm{p}<0.01)$, and similar to that with valsartan monotherapy $(4.8 \%)$ and placebo (5.9\%). Overall, reported adverse events were similar with amlodipine/valsartan and amlodipine monotherapy ( $44.1 \%$ and $45.7 \%$, respectively), but significantly higher than with valsartan monotherapy $(39.8 \%, \mathrm{p}<0.05)$. Only $1.8 \%$ of combi- nation therapy recipients discontinued treatment, which was similar to the rate of discontinuations in the placebo group $(2.1 \%)$. Peripheral oedema $(0.4 \%)$, vertigo $(0.2 \%)$ and headache $(0.1 \%)$ were the most common adverse events leading to study discontinuation in combination therapy recipients. The favourable effect on peripheral oedema of the dual mechanism of action of amlodipine and valsartan acting on arteries and veins was also supported by a study designed to evaluate the effect of valsartan in combination with amlodipine on objective measures of ankle oedema. ${ }^{[74]}$ In this study, amlodipine/valsartan $10 \mathrm{mg} / 160 \mathrm{mg}$ once daily for 6 weeks produced a significantly lower increase than amlodipine $10 \mathrm{mg}$ monotherapy in both measures, i.e. ankle foot volume $(6.8 \% \mathrm{vs}$ $23.0 \%, \mathrm{p}<0.01)$ and pretibial subcutaneous tissue pressure $(23.2 \%$ vs $75.5 \%, \mathrm{p}<0.001)$.

Studies have further shown that amlodipine/ valsartan provides additional BP control in hypertensive patients not controlled by an ACE inhibitor/CCB combination, ${ }^{[75]}$ and compared with valsartan monotherapy, ${ }^{[76]}$ amlodipine monotherapy ${ }^{[77]}$ or felodipine monotherapy. ${ }^{[77]}$ In a multicentre study of 133 patients with moderate hypertension who had not responded to 5 weeks' treatment with the ACE inhibitor/CCB combination of ramipril $5 \mathrm{mg}$ and felodipine $5 \mathrm{mg}$, an additional 5 weeks of treatment with amlodipine/ valsartan $10 \mathrm{mg} / 160 \mathrm{mg}$ resulted in clinically and statistically significant additional mean BP reductions of $15.4 / 7.0 \mathrm{mmHg} \quad(p<0.0001) .{ }^{[75]}$ Only $13 \%$ of patients achieved the target SBP of $<140 \mathrm{mmHg}$ with the ACE inhibitor/CCB treatment, compared with $69.5 \%$ of patients treated with amlodipine/valsartan. Treatment with amlodipine/valsartan was well tolerated, and no peripheral oedema was observed.

Amlodipine/valsartan combination therapy was significantly more effective at lowering $\mathrm{BP}$ than valsartan monotherapy in a double-blind study of patients with mild-to-moderate essential hypertension. ${ }^{[76]}$ A total of 947 patients were randomized to once-daily amlodipine/valsartan $5 \mathrm{mg} / 160 \mathrm{mg}$, amlodipine/valsartan $10 \mathrm{mg} / 160 \mathrm{mg}$ or valsartan $160 \mathrm{mg}$ monotherapy for 8 weeks. Mean SBP/DBP reductions from baseline were $12.2 / 9.6 \mathrm{mmHg}$ and $14.3 / 11.5 \mathrm{mmHg}$ for the 
two amlodipine/valsartan combinations (both $\mathrm{p}<0.0001$ ), and $8.3 / 6.7 \mathrm{mmHg}$ for valsartan monotherapy. There was a higher rate of successful responders (defined as a DBP $<90 \mathrm{mmHg}$ or $\geq 10 \mathrm{mmHg}$ decrease from baseline at study end) with combination therapy; $81 \%$ and $68 \%$ for amlodipine/valsartan $10 \mathrm{mg} / 160 \mathrm{mg}$ and $5 \mathrm{mg} / 160 \mathrm{mg}$, respectively, compared with $57 \%$ for valsartan $160 \mathrm{mg}$ monotherapy. In addition, a greater proportion of combination therapy versus monotherapy recipients had achieved DBP control (mean DBP $<90 \mathrm{mmHg}$ ) at study endpoint. ${ }^{[76]}$ Amlodipine/ valsartan $5 \mathrm{mg} / 160 \mathrm{mg}$ and valsartan $160 \mathrm{mg}$ monotherapy were similarly well tolerated, with adverse events being reported in $24.2 \%$ and $25.3 \%$ of patients treated with these regimens, respectively. Most events were mild or moderate in severity, and discontinuations due to adverse events were infrequent, occurring in $0.9 \%$ of patients in the amlodipine/valsartan $5 \mathrm{mg} / 160 \mathrm{mg}$ group and $0.6 \%$ in the valsartan $160 \mathrm{mg}$ group. Peripheral oedema was the most frequent adverse event leading to discontinuation and was dose dependent, occurring in $9.1 \%$ of amlodipine/ valsartan $10 \mathrm{mg} / 160 \mathrm{mg}$ recipients, compared with $0.9 \%$ and $1.3 \%$ of patients in the $5 \mathrm{mg} / 160 \mathrm{mg}$ combination and valsartan $160 \mathrm{mg}$ groups, respectively, and overall leading to discontinuation in only $1.0 \%$ of patients, ${ }^{[76]}$ reflecting the low rates of treatment discontinuation due to adverse events observed in clinical trials of amlodipine/valsartan.

Amlodipine/valsartan $5 \mathrm{mg} / 160 \mathrm{mg}$ has also been shown to produce clinically and statistically additional BP lowering in patients not adequately controlled by amlodipine $5 \mathrm{mg}$ or felodipine $5 \mathrm{mg}$ monotherapy. ${ }^{[77]}$ In this study of 214 patients with moderate essential hypertension (defined as SBP 160-179 $\mathrm{mmHg}$ ), $85 \%$ had not achieved an SBP of $<140 \mathrm{mmHg}$ after 4 weeks and were treated with amlodipine/valsartan $5 \mathrm{mg} / 160 \mathrm{mg}$ for a further 4 weeks. An additional mean BP reduction of $13.1 / 5.3 \mathrm{mmHg}$ was achieved with combination treatment $(\mathrm{p}<0.0001$ vs either monotherapy), and $51 \%$ of patients reached the target BP goal. Adverse events, mostly mild or moderate in severity, were low with both monotherapy and amlodipine/valsartan combination therapy, and were considered to be drug related in only $5.6 \%$ of patients in the monotherapy phase and $0.6 \%$ in the combination phase. The most common adverse events during combination treatment, regardless of relationship to study drug, were peripheral oedema $(0.6 \%)$, headache $(0.6 \%)$ and urinary tract infection $(1.1 \%)$. There were no clinically significant changes in laboratory values during the study.

In another study, both amlodipine/valsartan $5 \mathrm{mg} / 160 \mathrm{mg}$ (titrated to $10 \mathrm{mg} / 160 \mathrm{mg}$ if needed) and lisinopril/hydrochlorothiazide $10 \mathrm{mg} / 12.5 \mathrm{mg}$ (titrated to $20 \mathrm{mg} / 12.5 \mathrm{mg}$ if needed) significantly reduced $\mathrm{BP}$ and controlled $\mathrm{BP}$ at a similar rate in adult patients with stage 2 hypertension. ${ }^{[78]}$ After 6 weeks of treatment, mean reductions in seated $\mathrm{BP}$ were $-35.8 /-28.6 \mathrm{mmHg}$ and $-31.8 /-27.6 \mathrm{mmHg}$ with amlodipine/valsartan and lisinopril/hydrochlorothiazide, respectively (both $\mathrm{p}<0.001$ vs baseline). Both treatment regimens were generally well tolerated and resulted in similar rates of treatment response and DBP control.

In another recent study, a total of 894 patients not previously controlled on antihypertensive monotherapy were switched to fixed-dose amlodipine/valsartan (with or without the addition of hydrochlorothiazide). The primary outcome of BP control was attained in over $70 \%$ of patients at study end, with no significant difference between amlodipine/valsartan $5 \mathrm{mg} / 160 \mathrm{mg}$ and $10 \mathrm{mg} / 160 \mathrm{mg}$ groups $(72.7 \%$ and $74.8 \%$, respectively). ${ }^{[79]}$ Incremental reductions in BP were achieved throughout the study, irrespective of prior antihypertensive therapy, hypertension severity, diabetic status, age or body mass index. Fixed-dose amlodipine/valsartan was well tolerated; the most frequent adverse events were mild to moderate in severity and, as expected with a $\mathrm{CCB} / \mathrm{ARB}$ combination, consisted of peripheral oedema, headache, back pain, dizziness and muscle spasms. However, peripheral oedema considered to be related to treatment occurred in only $6.8 \%$ of amlodipine/valsartan $5 \mathrm{mg} / 160 \mathrm{mg}$ recipients, and led to discontinuation in $2.3 \%$. There was no treatment-related headache or dizziness at this dosage.

Amlodipine/valsartan $5 \mathrm{mg} / 160 \mathrm{mg}$ (increased to $10 \mathrm{mg} / 160 \mathrm{mg}$ if needed) produced similar BP reductions to irbesartan/hydrochlorothiazide $300 \mathrm{mg} / 12.5 \mathrm{mg}$ (increased to $300 \mathrm{mg} / 25 \mathrm{mg}$ if 
needed) in a 24-week study in very elderly (aged 75-89 years) patients with hypertension. ${ }^{[80]}$ However, amlodipine/valsartan had advantages in terms of less pronounced orthostatic BP changes and absence of metabolic adverse events. Although there was no difference between the two combinations in terms of reducing sitting and lying BP, mean BP changes after moving from the lying to the standing position were significantly greater in the irbesartan/hydrochlorothiazide group $(-17.2 /-9.1 \mathrm{mmHg})$ than in the amlodipine/ valsartan group $(-10.1 /-1.9 \mathrm{mmHg}, \mathrm{p}<0.05$ for SBP and $p<0.01$ for DBP vs irbesartan/ hydrochlorothiazide). Both regimens provided a persistent and smooth antihypertensive effect throughout the dosing period, as indicated by 24-hour ambulatory BP monitoring. Furthermore, clinic and ambulatory heart rate were not significantly affected by either combination. In addition, levels of serum potassium significantly decreased and uric acid significantly increased in irbesartan/hydrochlorothiazide recipients, representing adverse metabolic changes that were most probably associated with the diuretic. There were no significant changes in metabolic parameters with amlodipine/valsartan, supporting a lack of metabolic adverse effects with this combination. ${ }^{[80]}$

\section{Conclusions}

The use of combination antihypertensive therapy is widely acknowledged to be necessary to achieve BP targets associated with cardiovascular risk reduction in the majority of hypertensive patients. ${ }^{[1,2,12]}$ Accordingly, the benefits of initiating antihypertensive therapy with a twodrug combination chosen from therapeutic classes with complementary mechanisms of action is increasingly becoming regarded as a preferred first-line option for the effective management of hypertension. In this regard, the 2009 reappraisal of the European Guidelines on hypertension management recommends a more individually tailored approach for the initiation of antihypertensive therapy, especially in high-risk patients. ${ }^{[12]}$ Simplification of fixed-dose combinations contributes to better adherence, which is likely to be reflected in improved outcomes, and the combination of an inhibitor of the RAAS, such as an $\mathrm{ARB}$ or ACE inhibitor, with a long-acting CCB is a rational approach to the management of hypertension, providing effective BP control with good tolerability. Furthermore, the final results of the landmark ACCOMPLISH trial have established the benefit of initiating treatment with an RAAS inhibitor/CCB combination over an RAAS inhibitor/diuretic in preventing cardiovascular mortality and morbidity, including fatal and nonfatal stroke, myocardial infarction and cardiovascular-related deaths, despite similar reductions in BP. ${ }^{[48]}$ Not only is such a combination well tolerated and highly effective in helping patients to achieve target BP, ACCOMPLISH demonstrated a $20 \%$ relative risk reduction in cardiovascular events for the RAAS inhibitor/ CCB combination in this high-risk population. Amlodipine/valsartan has demonstrated BPlowering efficacy in diverse patient populations with hypertension and is associated with greater $\mathrm{BP}$ reductions and better $\mathrm{BP}$ control than the respective monotherapies, in conjunction with a favourable tolerability profile. Amlodipine/ valsartan is a rational and convenient treatment option for the effective management of patients with hypertension.

\section{Acknowledgements}

The author has received honoraria from Merck Sharp \& Dohme, Pfizer, Servier, Bayer and Novartis. Medical writing services for this manuscript were provided by Ray Hill, inScience Communications, a Wolters Kluwer business. Funding for this service was provided by Bial Farmacêutica, Portugal.

\section{References}

1. Chobanian AV, Bakris GL, Black HR, et al. The seventh report of the Joint National Committee on prevention, detection, evaluation, and treatment of high blood pressure: the JNC 7 report. JAMA 2003; 289 (19): 2560-72

2. Mancia G, De Backer G, Dominiczak A, et al. 2007 guidelines for the management of arterial hypertension: the Task Force for the Management of Arterial Hypertension of the European Society of Hypertension (ESH) and of the European Society of Cardiology (ESC). Eur Heart J 2007; 28 (12): 1462-536

3. Neal B, MacMahon S, Chapman N. Effects of ACE inhibitors, calcium antagonists, and other blood-pressure-lowering 
drugs: results of prospectively designed overviews of randomised trials. Blood Pressure Lowering Treatment Trialists' Collaboration. Lancet 2000; 356 (9246): 1955-64

4. Turnbull F, Neal B, Algert C, et al. Effects of different blood pressure-lowering regimens on major cardiovascular events in individuals with and without diabetes mellitus: results of prospectively designed overviews of randomized trials. Arch Intern Med 2005; 165(12): 1410-9

5. Staessen JA, Wang JG, Thijs L. Cardiovascular prevention and blood pressure reduction: a quantitative overview updated until 1 March 2003. J Hypertens 2003; 21(6): 1055-76

6. ALLHAT Collaborative Research Group. Major outcomes in high-risk hypertensive patients randomized to angiotensin-converting enzyme inhibitor or calcium channel blocker vs diuretic: the Antihypertensive and Lipid-Lowering Treatment to Prevent Heart Attack Trial (ALLHAT). JAMA 2002; 288 (23): 2981-97

7. Dahlof B, Devereux RB, Kjeldsen SE, et al. Cardiovascular morbidity and mortality in the Losartan Intervention For Endpoint reduction in hypertension study (LIFE): a randomised trial against atenolol. Lancet 2002; 359 (9311): 995-1003

8. Progress Collaborative Group. Randomised trial of a perindopril-based blood-pressure-lowering regimen among 6,105 individuals with previous stroke or transient ischaemic attack. Lancet 2001; 358 (9287): 1033-41

9. Turnbull F. Effects of different blood-pressure-lowering regimens on major cardiovascular events: results of prospectively-designed overviews of randomised trials. Lancet 2003; 362 (9395): 1527-35

10. Whitworth JA. 2003 World Health Organization (WHO)/ International Society of Hypertension (ISH) statement on management of hypertension. J Hypertens 2003; 21 (11): 1983-92

11. National Collaborating Centre for Chronic Conditions. Hypertension: management of hypertension in adults in primary care. Partial update. London: Royal College of Physicians, 2006

12. Mancia G, Laurent S, Agabiti-Rosei E, et al. Reappraisal of European guidelines on hypertension management: a European Society of Hypertension Task Force document. J Hypertens 2009; 27: 2121-58

13. Stankus V, Hemmelgarn B, Campbell NR, et al. Reducing costs and improving hypertension management. Can J Clin Pharmacol 2009; 16 (1): e151-5

14. Bangalore S, Kamalakkannan G, Parkar S, et al. Fixed-dose combinations improve medication compliance: a metaanalysis. Am J Med 2007; 120 (8): 713-9

15. Waeber B, Detry JM, Dahlof B, et al. Felodipine-metoprolol combination tablet: a valuable option to initiate antihypertensive therapy? Am J Hypertens 1999; 12 (9 Pt 1): 915-20

16. Waeber B, Ruilope LM. Amlodipine and valsartan as components of a rational and effective fixed-dose combination. Vasc Health Risk Manag 2009; 5 (1): 165-74

17. Wald DS, Law M, Morris JK, et al. Combination therapy versus monotherapy in reducing blood pressure: metaanalysis on 11,000 participants from 42 trials. Am J Med 2009; 122 (3): 290-300

18. Frampton JE, Scott LJ. Amlodipine/valsartan single-pill combination: a review of its use in the management of hypertension. Am J Cardiovasc Drugs 2009; 9 (5): 309-30
19. Jamerson KA, Nwose O, Jean-Louis L, et al. Initial angiotensin-converting enzyme inhibitor/calcium channel blocker combination therapy achieves superior blood pressure control compared with calcium channel blocker monotherapy in patients with stage 2 hypertension. Am J Hypertens 2004; 17 (6): 495-501

20. Messerli FH, Oparil S, Feng Z. Comparison of efficacy and side effects of combination therapy of angiotensin-converting enzyme inhibitor (benazepril) with calcium antagonist (either nifedipine or amlodipine) versus high-dose calcium antagonist monotherapy for systemic hypertension. Am J Cardiol 2000; 86 (11): 1182-7

21. Philipp T, Smith TR, Glazer R, et al. Two multicenter, 8-week, randomized, double-blind, placebo-controlled, parallel-group studies evaluating the efficacy and tolerability of amlodipine and valsartan in combination and as monotherapy in adult patients with mild to moderate essential hypertension. Clin Ther 2007; 29 (4): 563-80

22. Waeber B, Feihl F, Ruilope LM. Fixed-dose combinations as initial therapy for hypertension: a review of approved agents and a guide to patient selection. Drugs 2009; 69 (13): 1761-76

23. Nathan S, Pepine CJ, Bakris GL. Calcium antagonists: effects on cardio-renal risk in hypertensive patients. Hypertension 2005; 46 (4): 637-42

24. Ram CV. Antihypertensive drugs: an overview. Am J Cardiovasc Drugs 2002; 2 (2): 77-89

25. Brewster UC, Setaro JF, Perazella MA. The renin-angiotensin-aldosterone system: cardiorenal effects and implications for renal and cardiovascular disease states. Am J Med Sci 2003; 326 (1): 15-24

26. Schmieder RE, Hilgers KF, Schlaich MP, et al. Reninangiotensin system and cardiovascular risk. Lancet 2007; 369 (9568): 1208-19

27. Chrysant SG. Using fixed-dose combination therapies to achieve blood pressure goals. Clin Drug Investig 2008; 28 (11): 713-34

28. Ferrari R. Angiotensin-converting enzyme inhibition in cardiovascular disease: evidence with perindopril. Expert Rev Cardiovase Ther 2005; 3 (1): 15-29

29. Gradman AH, Cutler NR, Davis PJ, et al. Combined enalapril and felodipine extended release (ER) for systemic hypertension. Enalapril-Felodipine ER Factorial Study Group. Am J Cardiol 1997; 79 (4): 431-5

30. Poisson P, Bauer B, Schueler E, et al. Ramipril and felodipine: a comparison of the efficacy and safety of monotherapy versus combination therapy. Curr Med Res Opinion 1996; 13 (8): 445-56

31. Pool J, Kaihlanen P, Lewis G, et al. Once-daily treatment of patients with hypertension: a placebo-controlled study of amlodipine and benazepril vs amlodipine or benazepril alone. J Hum Hypertens 2001; 15 (7): 495-8

32. Roca-Cusachs A, Torres F, Horas M, et al. Nitrendipine and enalapril combination therapy in mild to moderate hypertension: assessment of dose-response relationship by a clinical trial of factorial design. J Cardiovase Pharmacol 2001; 38 (6): 840-9

33. Scholze J, Zilles P, Compagnone D. Verapamil SR and trandolapril combination therapy in hypertension: a clinical trial of factorial design. German Hypertension Study Group. Br J Clin Pharmacol 1998; 45 (5): 491-5 
34. Ueng KC, Lin LC, Voon WC, et al. An eight-week, multicenter, randomized, double-blind study to evaluate the efficacy and tolerability of fixed-dose amlodipine/benazepril combination in comparison with amlodipine as first-line therapy in Chinese patients with mild to moderate hypertension. Blood Press 2008; Suppl. 1: 24-31

35. Burnier M, Brunner HR. Angiotensin II receptor antagonists. Lancet 2000; 355 (9204): 637-45

36. Schmieder RE. Mechanisms for the clinical benefits of angiotensin II receptor blockers. Am J Hypertens 2005; 18 (5 Pt 1): 720-30

37. Black HR, Bailey J, Zappe D, et al. Valsartan: more than a decade of experience. Drugs 2009; 69 (17): 2393-414

38. Ibrahim MM. RAS inhibition in hypertension. J Hum Hypertens 2006; 20 (2): 101-8

39. Epstein BJ, Vogel K, Palmer BF. Dihydropyridine calcium channel antagonists in the management of hypertension. Drugs 2007; 67 (9): 1309-27

40. Lindholm LH, Ibsen H, Dahlof B, et al. Cardiovascular morbidity and mortality in patients with diabetes in the Losartan Intervention For Endpoint reduction in hypertension study (LIFE): a randomised trial against atenolol. Lancet 2002; 359 (9311): 1004-10

41. Oparil S, Weber M. Angiotensin receptor blocker and dihydropyridine calcium channel blocker combinations: an emerging strategy in hypertension therapy. Postgrad Med 2009; 121 (2): 25-39

42. Stump CS, Hamilton MT, Sowers JR. Effect of antihypertensive agents on the development of type 2 diabetes mellitus. Mayo Clin Proc 2006; 81 (6): 796-806

43. Ostergren J. Renin-angiotensin-system blockade in the prevention of diabetes. Diabetes Res Clin Pract 2007; 76 Suppl. 1: S13-21

44. Abuissa H, Jones PG, Marso SP, et al. Angiotensinconverting enzyme inhibitors or angiotensin receptor blockers for prevention of type 2 diabetes: a meta-analysis of randomized clinical trials. J Am Coll Cardiol 2005; 46 (5): $821-6$

45. Waeber B. Combination therapy with ACE inhibitors/ angiotensin II receptor antagonists and diuretics in hypertension. Expert Rev Cardiovasc Ther 2003; 1 (1): 43-50

46. Lithell H, Hansson L, Skoog I, et al. The Study on Cognition and Prognosis in the Elderly (SCOPE): principal results of a randomized double-blind intervention trial J Hypertens 2003; 21 (5): 875-86

47. Patel A, MacMahon S, Chalmers J, et al. Effects of a fixed combination of perindopril and indapamide on macrovascular and microvascular outcomes in patients with type 2 diabetes mellitus (the ADVANCE trial): a randomised controlled trial. Lancet 2007; 370 (9590): 829-40

48. Jamerson K, Weber MA, Bakris GL, et al. Benazepril plus amlodipine or hydrochlorothiazide for hypertension in high-risk patients. N Engl J Med 2008; 359 (23): 2417-28

49. Jamerson K, Bakris GL, Dahlof B, et al. Exceptional early blood pressure control rates: the ACCOMPLISH trial. Blood Press 2007; 16 (2): 80-6

50. Yusuf S, Teo KK, Pogue J, et al. Telmisartan, ramipril, or both in patients at high risk for vascular events. N Engl J Med 2008; 358 (15): 1547-59
51. Reboldi G, Angeli F, Cavallini C, et al. Comparison between angiotensin-converting enzyme inhibitors and angiotensin receptor blockers on the risk of myocardial infarction, stroke and death: a meta-analysis. J Hypertens 2008; 26 (7): $1282-9$

52. Volpe M, Tocci G, Sciarretta S, et al. Angiotensin II receptor blockers and myocardial infarction: an updated analysis of randomized clinical trials. J Hypertens 2009; 27 (5): $941-6$

53. Dahlof B, Sever PS, Poulter NR, et al. Prevention of cardiovascular events with an antihypertensive regimen of amlodipine adding perindopril as required versus atenolol adding bendroflumethiazide as required, in the AngloScandinavian Cardiac Outcomes Trial-Blood Pressure Lowering Arm (ASCOT-BPLA): a multicentre randomised controlled trial. Lancet 2005; 366 (9489): 895-906

54. Gupta AK, Dahlof B, Dobson J, et al. Determinants of newonset diabetes among 19,257 hypertensive patients randomized in the Anglo-Scandinavian Cardiac Outcomes Trial-Blood Pressure Lowering Arm and the relative influence of antihypertensive medication. Diabetes Care 2008; 31 (5): 982-8

55. Pepine CJ, Handberg EM, Cooper-DeHoff RM, et al. A calcium antagonist vs a non-calcium antagonist hypertension treatment strategy for patients with coronary artery disease. The International Verapamil-Trandolapril Study (INVEST): a randomized controlled trial. JAMA 2003; 290 (21): 2805-16

56. Solomon SD, Verma A, Desai A, et al. Effect of intensive versus standard blood pressure lowering on diastolic function in patients with uncontrolled hypertension and diastolic dysfunction. Hypertension 2010; 55 (2): 241-8

57. Haria M, Wagstaff AJ. Amlodipine: a reappraisal of its pharmacological properties and therapeutic use in cardiovascular disease. Drugs 1995; 50 (3): 560-86

58. Cohn JN, Tognoni G. A randomized trial of the angiotensinreceptor blocker valsartan in chronic heart failure. N Engl J Med 2001; 345 (23): 1667-75

59. Latini R, Masson S, Anand I, et al. Effects of valsartan on circulating brain natriuretic peptide and norepinephrine in symptomatic chronic heart failure: the Valsartan Heart Failure Trial (Val-HeFT). Circulation 2002; 106 (19): 2454-8

60. Maggioni AP, Anand I, Gottlieb SO, et al. Effects of valsartan on morbidity and mortality in patients with heart failure not receiving angiotensin-converting enzyme inhibitors. J Am Coll Cardiol 2002; 40 (8): 1414-21

61. Maggioni AP, Latini R, Carson PE, et al. Valsartan reduces the incidence of atrial fibrillation in patients with heart failure: results from the Valsartan Heart Failure Trial (ValHeFT). Am Heart J 2005; 149 (3): 548-57

62. Wong M, Staszewsky L, Latini R, et al. Valsartan benefits left ventricular structure and function in heart failure: ValHeFT echocardiographic study. J Am Coll Cardiol 2002; 40 (5): 970-5

63. Pfeffer MA, McMurray JJ, Velazquez EJ, et al. Valsartan, captopril, or both in myocardial infarction complicated by heart failure, left ventricular dysfunction, or both. N Engl J Med 2003; 349 (20): 1893-906

64. Julius S, Kjeldsen SE, Weber M, et al. Outcomes in hypertensive patients at high cardiovascular risk treated with 
regimens based on valsartan or amlodipine: the VALUE randomised trial. Lancet 2004; 363 (9426): 2022-31

65. Julius S, Weber MA, Kjeldsen SE, et al. The Valsartan Antihypertensive Long-Term Use Evaluation (VALUE) trial: outcomes in patients receiving monotherapy. Hypertension 2006; 48 (3): 385-91

66. Weber MA, Julius S, Kjeldsen SE, et al. Blood pressure dependent and independent effects of antihypertensive treatment on clinical events in the VALUE trial. Lancet 2004; 363 (9426): 2049-51

67. Kjeldsen SE, Julius S, Mancia G, et al. Effects of valsartan compared to amlodipine on preventing type 2 diabetes in high-risk hypertensive patients: the VALUE trial. J Hypertens 2006; 24 (7): 1405-12

68. Mochizuki S, Dahlof B, Shimizu M, et al. Valsartan in a Japanese population with hypertension and other cardiovascular disease (Jikei Heart Study): a randomised, openlabel, blinded endpoint morbidity-mortality study. Lancet 2007; 369 (9571): 1431-9

69. Sawada T, Yamada H, Dahlof B, et al. Effects of valsartan on morbidity and mortality in uncontrolled hypertensive patients with high cardiovascular risks: KYOTO HEART study. Eur Heart J 2009; 30 (20): 2461-9

70. Kohlmann Jr O, Oigman W, Mion D, et al. The "LOTHAR" study: evaluation of efficacy and tolerability of the fixed combination of amlodipine and losartan in the treatment of essential hypertension. Arq Bras Cardiol 2006; 86 (1): $39-51$

71. Sharma A, Bagchi A, Kinagi SB, et al. Results of a comparative, phase III, 12-week, multicenter, prospective, randomized, double-blind assessment of the efficacy and tolerability of a fixed-dose combination of telmisartan and amlodipine versus amlodipine monotherapy in Indian adults with stage II hypertension. Clin Ther 2007; 29 (12): 2667-76

72. Smith TR, Philipp T, Vaisse B, et al. Amlodipine and valsartan combined and as monotherapy in stage 2, elderly, and black hypertensive patients: subgroup analyses of 2 randomized, placebo-controlled studies. J Clin Hypertens (Greenwich) 2007; 9 (5): 355-64
73. Plosker G, Robinson D. Amlodipine/valsartan fixed-dose combination in hypertension. Drugs 2008; 68 (3): 378-81

74. Fogari R, Zoppi A, Derosa G, et al. Effect of valsartan addition to amlodipine on ankle oedema and subcutaneous tissue pressure in hypertensive patients. J Hum Hypertens 2007; 21 (3): 220-4

75. Trenkwalder $\mathrm{P}$, Schaetzl R, Borbas E, et al. Combination of amlodipine $10 \mathrm{mg}$ and valsartan $160 \mathrm{mg}$ lowers blood pressure in patients with hypertension not controlled by an ACE inhibitor/CCB combination. Blood Press 2008; Suppl. 2: 13-21

76. Sinkiewicz W, Glazer RD, Kavoliuniene A, et al. Efficacy and tolerability of amlodipine/valsartan combination therapy in hypertensive patients not adequately controlled on valsartan monotherapy. Curr Med Res Opin 2009; 25 (2): $315-24$

77. Brachmann J, Ansari A, Mahla G, et al. Effective and safe reduction of blood pressure with the combination of amlodipine $5 \mathrm{mg}$ and valsartan $160 \mathrm{mg}$ in hypertensive patients not controlled by calcium channel blocker monotherapy. Adv Ther 2008; 25 (5): 399-411

78. Poldermans D, Glazes R, Kargiannis S, et al. Tolerability and blood pressure-lowering efficacy of the combination of amlodipine plus valsartan compared with lisinopril plus hydrochlorothiazide in adult patients with stage 2 hypertension. Clin Ther 2007; 29 (2): 279-89

79. Allemann Y, Fraile B, Lambert M, et al. Efficacy of the combination of amlodipine and valsartan in patients with hypertension uncontrolled with previous monotherapy: the Exforge in Failure after Single Therapy (EX-FAST) study. J Clin Hypertens (Greenwich) 2008; 10 (3): 185-94

80. Fogari R, Zoppi A, Mugellini A, et al. Efficacy and safety of two treatment combinations of hypertension in very elderly patients. Arch Gerontol Geriatr 2009; 48 (3): 401-5

Correspondence: Dr Pedro Marques da Silva, Núcleo de Investigação Arterial, Medicina IV-Hospital de St ${ }^{\mathrm{a}}$ Marta, CHLC, EPE. Rua de Santa Marta, n 50 1169-024 Lisboa, Portugal.

E-mail: Pedro.Silva@hsmarta.min-saude.pt 
Copyright of Clinical Drug Investigation is the property of ADIS International Limited and its content may not be copied or emailed to multiple sites or posted to a listserv without the copyright holder's express written permission. However, users may print, download, or email articles for individual use. 